\title{
Automatic Queuing Model for Banking Applications
}

\author{
Dr. Ahmed S. A. AL-Jumaily \\ Department of Multimedia \\ IT College, Ahlia University \\ Manama, Bahrain
}

\author{
Dr. Huda K. T. AL-Jobori \\ Department of Information Technology \\ IT College, Ahlia University \\ Manama, Bahrain
}

\begin{abstract}
Queuing is the process of moving customers in a specific sequence to a specific service according to the customer need. The term scheduling stands for the process of computing a schedule. This may be done by a queuing based scheduler.

This paper focuses on the banks lines system, the different queuing algorithms that are used in banks to serve the customers, and the average waiting time. The aim of this paper is to build automatic queuing system for organizing the banks queuing system that can analyses the queue status and take decision which customer to serve. The new queuing architecture model can switch between different scheduling algorithms according to the testing results and the factor of the average waiting time. The main innovation of this work concerns the modeling of the average waiting time is taken into processing, in addition with the process of switching to the scheduling algorithm that gives the best average waiting time.
\end{abstract}

Keywords-Queuing Systems; Queuing System models; Queuing System Management; Scheduling Algorithms.

\section{INTRODUCTION}

Today banks are one of the most important units of the public. Since the foundational work of banks, many researchers try to get full advantage of any new technology to increase customer satisfaction. Therefore an active research has focused on analyzing the queues to optimize their operations and to reduce waiting time for customers [1,2,3].

This paper focuses on the bank lines system and the different queuing algorithms that used in banks to serve the customers. Most banks used standard queuing models. To avoid standing in a queue for a long time or in a wrong line, most banks use automatic queue system to give tickets to all customers. The customer can push a specific button in a tickets supplier device according to their needs.

The aim of this paper is to decrease customers waiting time by building a homogenous way that analyze the queue status and take decisions about which customer to serve by using the appropriate scheduling algorithm.

The rest of this paper is organized as follows. Section 2 consists of queuing systems characteristics, most common scheduling algorithms, and the queue models. Then our proposed queuing system model is shown in section 3 . Experimental results are shown in section 4, followed by brief conclusions and suggestions for future work are shown in section 5. Then the references are shown in section 6 .

\section{QUEUING SYSTEMS}

A queuing system consists of one or more servers that provide service to arriving customers. Figure 1 shows the characteristics of queuing system [4].

The population of customers may be finite (closed systems) or infinite (open systems). The arrival process describes how customers enter the system. The customers arrive to the service center in a random fashion.

Queue represents a certain number of customers waiting for service. The capacity of a queue is either limited or unlimited. Bank is an example of unlimited queue length.

The service is an activity requested by a customer, where each service takes a specific time. The scheduling algorithm is used to order the customers and to choose the next customer from the queue. The most common scheduling algorithms are $[4,5]$ :

a) FCFS (First Come First Serve): The customers are served in the order of their arrival, which is most visibly fair because all customers think of themselves as equal.

b) RSS (Random Selection for Service): In this algorithm, customers are selected for service at random, so each customer in the queue has the same probability of being selected for service irrespective of his/her arrival in the service system.

c) PRI (Priority Service): The customers are grouped in priority classes according to some external factors. The customer with the highest priority is served first.

d) SPF (Shortest Processed First): The algorithm assumes that the service times are known in advance. When several customers are waiting in the queue, the SPF algorithm picks the shortest service time first.

The departure represents the way customers leave the system.

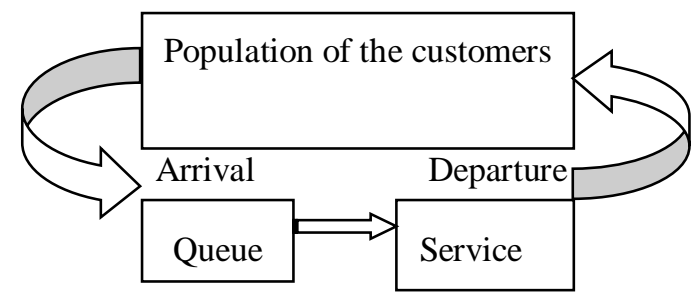

Figure 1: Simplest Queuing System 
In queuing system, there are many types of queue models such as $[5,6]$ :

a) SQ (Single Queue): In this model each customer waits till the service point is ready to take him for servicing.

b) MQ (Multiple Queues): In this model each customer tries to choose the shortest queue from a number of individual queues.

c) $D Q$ (Diffuse Queue): In this model each customer take a ticket from a ticket machine with single or multiple buttons each for specific service. After the customer registers his/her place in the queue by a ticket he/she will monitor the ticket number being served. The customers can not estimate when they will be served.

\section{The Proposed QueUing System ModeL}

We know present a new technique for queue management system in banks. Our technique is to builds an automatic queuing system that can test the status of the queuing system such as DQ and choose the appropriate algorithm among more than one scheduling algorithms that already defined in the system such as FCFS and SPF to select the next customer to be served during a specific period of time.

Selecting the scheduling algorithm depends on the testing results to achieve the best waiting time for all the available customers that are waiting to be served.

To achieve this goal we add additional components to the traditional queuing management system as shown in figure 2.

The suggested queuing system consists of the following components:

a) Customer area: In customer area the customer selects a service at the ticket dispenser via regular push buttons, and waits until his/her ticket number shown in a vision and/or audio notice for the number.

b) Queuing area: In queuing area the system uses the queuing algorithm that is chosen by the testing area to select one of the waiting customers.

c) Testing area: In testing area the system tests the status of the system according to the existing algorithms in the algorithms database and compares between all the result for the expected waiting and response time then selects the algorithm that gives the best waiting time.

d) Scheduling Algorithms Database area: All the needed scheduling algorithms, the testing result, and the customers numbers, are stored in the scheduling algorithms database area. The testing result and the customer's numbers are saved temporarily.

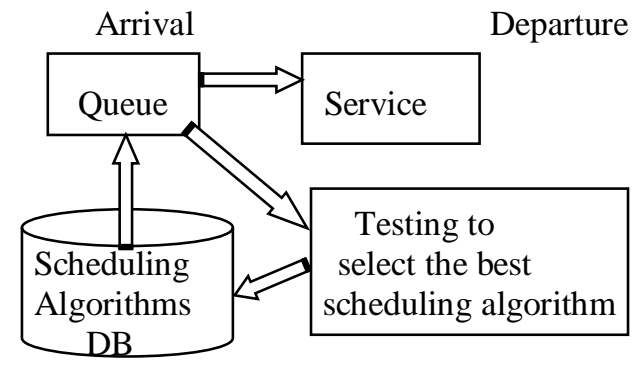

Figure 2: The new Queuing System

e) Service area: In service area the system serves the customer according to the different services that a bank can give as open an account, transaction, send money, deposit funds, balance, etc. Each service needs a specific time.

\section{EXPERIMENTAL RESULTS}

Simulations were carried to test the performance of the new proposed system. A database of two standard scheduling algorithms was developed to systematically evaluate the proposed system. For the purpose of illustrations, a comparison between the new system and the ordinary system (FCFS) that is used usually in most of the banks queuing systems.

In the proposed system, two scheduling algorithms are used (FCFS, SPF). For the purpose of calculation and reality a random number generation is used to generate a sequence of customers' arrival time and to choose randomly between three different services: open an account, transaction, and balance, with different period of time for each service: 15,10 , and 5 respectively.

The proposed system will test the queuing system using testing algorithm every specific period of time, let's conceder it 15 time unit, to select the appropriate scheduling algorithm i.e. either FCFS or SPF according to the average waiting time.

To test the proposed system we implement two case studies:

Case 1: After executing the random generator, a simulation snapshot for the queuing system is generated, the result are 20 customers with different arrival time starting from zero, and different service time as shown in table 1 .

After implementing the ordinary queuing system and the proposed queuing system on the above snapshot, the resulted Gantt chart for the ordinary queuing bank system that uses only FCFS algorithm, as shown in figure 3.

The new queuing system calculates the waiting time for each customer, then calculates the total waiting time and the average waiting time according to the two algorithms (FCFS, $\mathrm{SPF}$ ) each 15 time unit as shown in figure 4, it can switch between the two algorithms at the end of the time unit by selecting the algorithm with the minimum average waiting time.

TABLE 1: A SNAPSHOT FOR THE GENERATED QUEUING SYSTEM

\begin{tabular}{|c|c|c|c|}
\hline Customer & $\begin{array}{c}\text { Arrival } \\
\text { Time }\end{array}$ & $\begin{array}{c}\text { Service } \\
\text { Time }\end{array}$ & $\begin{array}{c}\text { Service } \\
\text { Type }\end{array}$ \\
\hline C1 & 0 & 10 & Transaction \\
\hline C2 & 5 & 15 & Open account \\
\hline C3 & 8 & 5 & Balance \\
\hline C4 & 15 & 10 & Transaction \\
\hline C5 & 17 & 5 & Balance \\
\hline C6 & 19 & 5 & Balance \\
\hline C7 & 20 & 10 & Transaction \\
\hline C8 & 25 & 5 & Balance \\
\hline C9 & 28 & 5 & Balance \\
\hline
\end{tabular}




\begin{tabular}{|c|c|c|c|}
\hline $\mathrm{C} 10$ & 30 & 10 & Transaction \\
\hline $\mathrm{C} 11$ & 40 & 15 & Open account \\
\hline $\mathrm{C} 12$ & 42 & 5 & Balance \\
\hline $\mathrm{C} 13$ & 43 & 5 & Balance \\
\hline $\mathrm{C} 14$ & 44 & 5 & Balance \\
\hline $\mathrm{C} 15$ & 110 & 15 & Open account \\
\hline $\mathrm{C} 16$ & 111 & 10 & Transaction \\
\hline $\mathrm{C} 17$ & 112 & 5 & Balance \\
\hline $\mathrm{C} 18$ & 113 & 5 & Balance \\
\hline $\mathrm{C} 19$ & 114 & 5 & Balance \\
\hline $\mathrm{C} 20$ & 115 & 10 & Transaction \\
\hline
\end{tabular}

FCFS

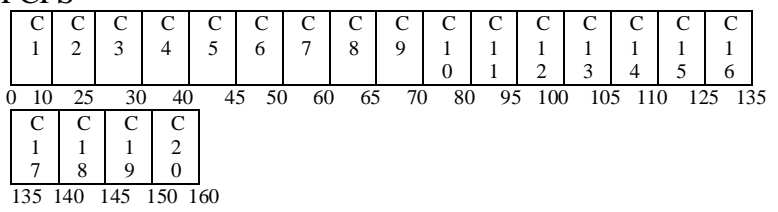

Figure 3: Ordinary queuing system Gantt chart

a. Testing $1^{\text {st }}$ group using the two scheduling algorithms FCFS

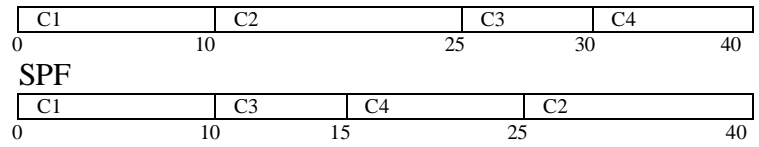

b. Testing $2^{\text {nd }}$ group using the two scheduling algorithms FCFS

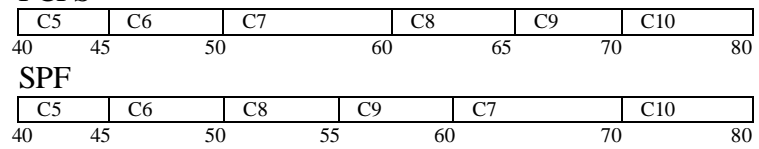

c. Testing $3^{\text {rd }}$ group using the two scheduling algorithms FCFS

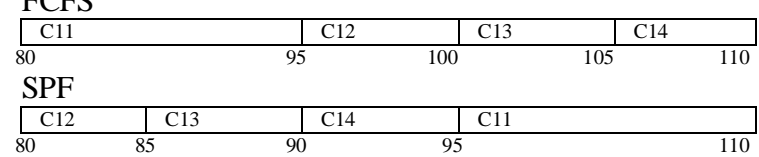

d. Testing $4^{\text {th }}$ group using the two scheduling algorithms FCFS

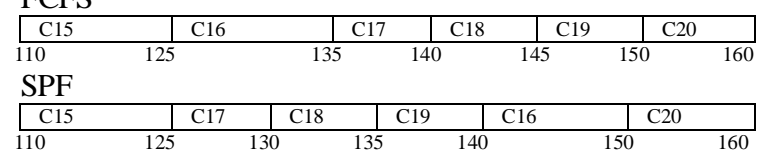

Figure 4: The new queuing system Gantt chart

$$
(\mathrm{a}, \mathrm{b}, \mathrm{c}, \mathrm{d})
$$

Through the extensive experiments conducted, the primary goal is to determine the ability of the new queuing system against the ordinary queuing system.

Figure 5 show that the new approach decreases the average waiting time, compared with the ordinary queuing system.

Equation 1 is used to calculate the waiting time for each customer [7]:

$$
\text { CWT } \mathrm{i}=\operatorname{SSTC} \mathrm{i}-\text { ATC } \mathrm{i}
$$

Where:
CWT is a Customer Waiting Time

SSTC is Start Serving Time for a Customer

ATC is Arrival Time for a Customer

$\mathrm{i}$ is The ith Customer number

The average waiting time for each group of customers is calculated using equation 2 .

$$
\mathrm{AWT}=\left(\sum \mathrm{CWT}_{\mathrm{i}}\right) / \mathrm{TN}
$$

Where:

AWT is Average Waiting Time

CWT is a Customer Waiting Time

TN is total number of customers served

$\mathrm{i}$ is the number of customer

Table 2 shows the average waiting time for the ordinary queuing system and the new queuing system.

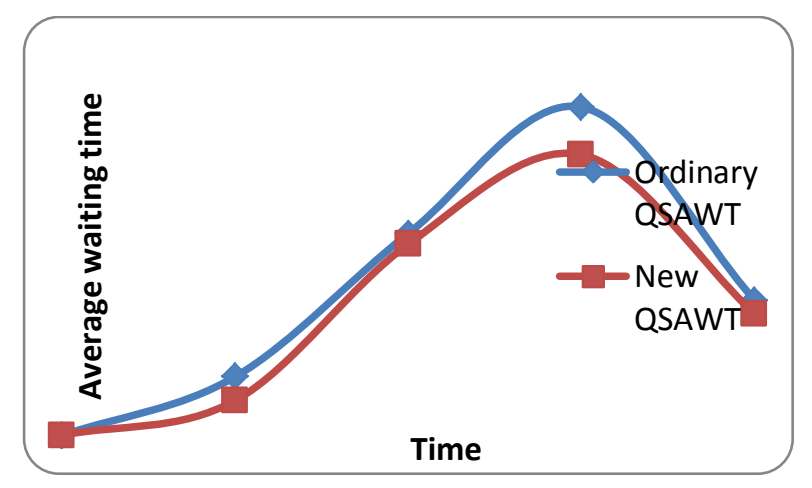

Figure 5: The different between the ordinary queuing system and the new queuing system

TABLE 2: THE AVERAGE WAITING TIME COMPARISON BETWEEN THE ORDINARY QUEUING SYSTEM AND THE NEW AUTOMATIC QUEUING SYSTEM

\begin{tabular}{|c|c|c|c|}
\hline Time Slice & $\begin{array}{c}\text { Ordinary Queuing } \\
\text { System Average } \\
\text { Waiting Time } \\
\text { and } \\
\text { Algorithm }\end{array}$ & $\begin{array}{c}\text { New Automatic } \\
\text { Queuing System } \\
\text { Average Waiting } \\
\text { Time } \\
\text { and Algorithm }\end{array}$ & $\begin{array}{c}\text { The } \\
\text { Difference } \\
\text { Between } \\
\text { Ordinary } \\
\text { and } \\
\text { New } \\
\text { Algorithm }\end{array}$ \\
\hline $1^{\text {st } G r o u p ~}$ & $9.25 /$ FCFS & $5.5 /$ SPF & 3.75 \\
\hline $2^{\text {nd }}$ Group & $31.83 /$ FCFS & $30.16 /$ SPF & 1.67 \\
\hline $3^{\text {rd }}$ Group & $52.75 /$ FCFS & $45.25 /$ SPF & 7.5 \\
\hline $4^{\text {th }}$ Group & $21.33 /$ FCFS & $19.166 / \mathrm{SPF}$ & 2.164 \\
\hline $\begin{array}{c}\text { Total } \\
\text { Average } \\
\text { waiting } \\
\text { time }\end{array}$ & 28.45 & 24.95 & 3.5 \\
\hline
\end{tabular}

Case 2: After executing the random generator, a simulation snapshot for the queuing system is generated, the result are 12 customers with different arrival time starting from zero, and different service time as shown in table 3 . 
After implementing the ordinary queuing system and the proposed system on the above snapshot, we compare the results of waiting time and average waiting time. The results of compression between them are shown in figure 6, figure 7 , figure 8 , and table 4 respectively.

TABLE 3: A SNAPSHOT FOR THE GENERATED QUEUING SYSTEM

\begin{tabular}{|c|c|c|c|}
\hline Customer & $\begin{array}{c}\text { Arrival } \\
\text { Time }\end{array}$ & $\begin{array}{c}\text { Service } \\
\text { Time }\end{array}$ & $\begin{array}{c}\text { Service } \\
\text { Type }\end{array}$ \\
\hline C1 & 0 & 15 & Open account \\
\hline C2 & 3 & 5 & Balance \\
\hline C3 & 9 & 15 & Open account \\
\hline C4 & 12 & 15 & Open account \\
\hline C5 & 14 & 10 & Transaction \\
\hline C6 & 18 & 5 & Balance \\
\hline C7 & 25 & 5 & Balance \\
\hline C8 & 28 & 5 & Balance \\
\hline C9 & 29 & 5 & Balance \\
\hline C10 & 42 & 10 & Transaction \\
\hline C11 & 43 & 10 & Transaction \\
\hline C12 & 44 & 5 & Balance \\
\hline
\end{tabular}

FCFS

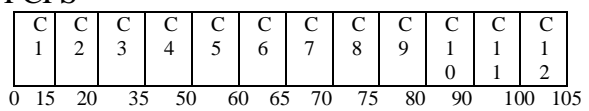

Figure 6: Ordinary queuing system Gantt chart

a. Testing first 15 time unit using the two scheduling algorithms

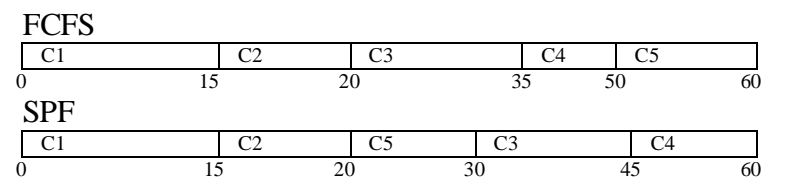

b. Testing $2^{\text {nd }} 15$ time unit using the two scheduling algorithms

FCFS
\begin{tabular}{|l|ll|ll|ll|}
\hline C 6 & C 7 & & C 8 & \multicolumn{1}{l|}{ C 9} & \\
60 & 65 & 70 & & 75 & & 80 \\
SPF & & & & \\
\hline C 6 & C 7 & C 8 & & C 9 & \\
\hline 60 & 65 & 70 & & 75 & & 80 \\
\hline
\end{tabular}

c. Testing $3^{\text {rd }} 15$ time unit using the two scheduling algorithms

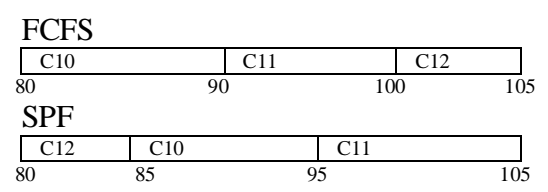

Figure 7: The new queuing system Gantt chart $(\mathrm{a}, \mathrm{b}, \mathrm{c}, \mathrm{d})$

Table 4 shows the average waiting time for the ordinary queuing system and the new queuing system, it illustrate how the new queuing system fillips between the two different scheduling algorithms according to the average waiting time.

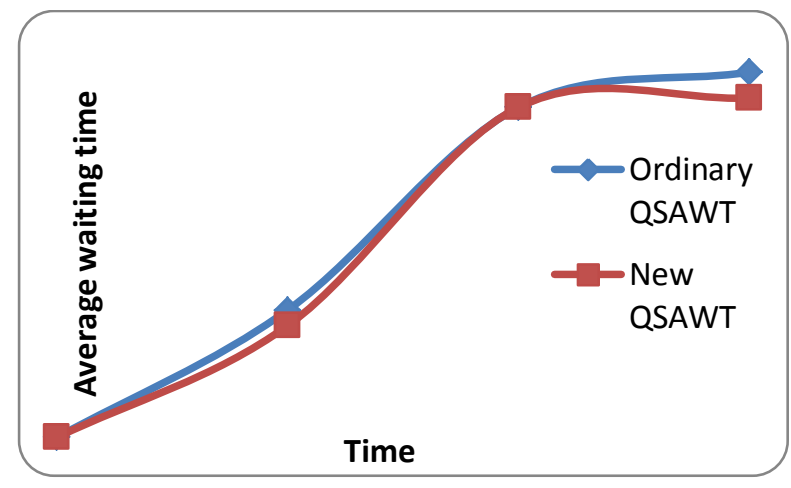

Figure 8: The different between the ordinary queuing system and the new queuing system

TABLE 4: RESULTS SHOWS THE AVERAGE WAITING TIME COMPARISON BETWEEN THE ORDINARY QUEUING SYSTEM AND THE NEW AUTOMATIC QUEUING SYSTEM

\begin{tabular}{|c|c|c|c|}
\hline $\begin{array}{c}\text { Time } \\
\text { Slice }\end{array}$ & $\begin{array}{c}\text { Ordinary Queuing } \\
\text { System Average } \\
\text { Waiting Time } \\
\text { and } \\
\text { Algorithm }\end{array}$ & $\begin{array}{c}\text { New Automatic } \\
\text { Queuing System } \\
\text { Average Waiting } \\
\text { Time } \\
\text { and Algorithm }\end{array}$ & $\begin{array}{c}\text { The } \\
\text { Difference } \\
\text { Between } \\
\text { Ordinary } \\
\text { and } \\
\text { New } \\
\text { Algorithm }\end{array}$ \\
\hline $1^{\text {st }}$ Group & $16.4 /$ FCFS & $14.4 /$ SPF & 2 \\
\hline $2^{\text {nd }}$ Group & $42.5 /$ FCFS & $42.5 /$ FCFS & 0 \\
\hline $3^{\text {rd }}$ Group & $47 /$ FCFS & $43.66 /$ SPF & 3.34 \\
\hline $\begin{array}{c}\text { Total } \\
\text { Average } \\
\text { waiting } \\
\text { time }\end{array}$ & 32.75 & 31.083 & 1.667 \\
\hline
\end{tabular}

\section{CONCLUSION AND FUTURE WORK}

In a queue system, the balance between dealing with all customers fairly and the performance of the system is very important. Sometimes the performance of the system is more important than dealing with the customers fairly.

In this paper, we have presented a new technique for queuing system called automatic queuing system. The proposed technique showed improvements in average waiting time.

It will be more effect to add more factors in testing to take the right decision for choosing one of the available scheduling algorithms, such as throughput, utilization, and response time.

Also adding more scheduling algorithms to the system database will be useful.

\section{REFERENCES}

[1] B. Goluby, and R. Preston McAfeez, "Firms, queues, and coffee breaks: A flow model of corporate activity with delays", Springer-Verlag, vol.15, pp. 59-89, March 2011.

[2] A. Mobarek, " E-banking practices and customer satisfaction- a case study in botswana", $20^{\text {th }}$ Australasian Finance \& Banking Conference, 2007.

[3] O. Luštšik, "E-banking in estonia: Reasons and benefits of the rapid growth", University of Tartu, kroon and economy, vol. 3, pp.24-36, 2003.

[4] K. Sanjay, Bose, "An introduction to queuing systems", Springer, 2002. 
[5] F. Mohamad, "Front desk customer service for queue management system", Master Thesis, University Malaysia Pahang, November, 2007.

[6] A. Allen, "Probability, statistics, and queuing theory with computer science applications", Academic Press Inc., Second Edition, 1990.
[7] A. Willig, "A short introduction to queuing theory", Technical University Berlin, Telecommunication Networks Group Sekr. FT 5-2, Berlin, July 